\title{
Melkersson-Rosenthal syndrome associated to Hashimoto's thyroiditis
}

\author{
Salem Bouomrani ${ }^{1,2 *}$, Ines Lamloum ${ }^{1,2}$ and Rim Mesfar ${ }^{1,2}$ \\ ${ }^{1}$ Department of Internal medicine, Military Hospital of Gabes, Gabes 6000, Tunisia \\ ${ }^{2}$ Sfax Faculty of Medicine, University of Sfax, Sfax 3029, Tunisia
}

\begin{abstract} syndrome. The association with autoimmune thyroiditis remains exceptional and unusual. and systemic glucosteroids.

\section{Introduction}

Melkersson-Rosenthal syndrome (MRS) is a rare neuromucocutaneous granulomatous disorder classically defined by the triad: fissured tongue (lingua plicata), recurrent orofacial edema, and relapsing facial paralysis [1,2].

The pathophysiology of this syndrome is still unknown. Association with other dysimmune disorders such as systemic lupus erythematosus, multiple sclerosis, Crohn's disease, sarcoidosis, and anterior uveitis was reported suggesting a dysimmunitary/immunological origin to this syndrome $[2,3]$. The association with autoimmune thyroiditis, however, remains exceptional and unusual $[3,4]$.
\end{abstract}

Melkersson-Rosenthal syndrome (MRS) is a rare neuromucocutaneous granulomatous disorder classically defined by the triad: fissured tongue (lingua plicata), recurrent orofacial edema, and relapsing facial paralysis. Association with other dysimmune disorders was reported suggesting an immunological origin to this

We report the original case of an MRS associated with Hashimoto autoimmune thyroiditis in a 39-year-old Tunisian man with favorable outcome under thyroxine

A dosage of thyroid hormones and a screening for anti-thyroid antibodies would be useful in patients with an MRS.

We report the original case of an MRS associated with Hashimoto autoimmune thyroiditis.

\section{Case report}

A 39-year-old man with no pathological medical history, was referred to our department for exploration of alternating unilateral peripheral facial nerve palsy (two episodes of left facial paralysis and one episode of right facial paralysis in two years).

Somatic examination noted a macroglossia with a large dorsal and central fissure of the long (Figure 1) and teeth marks on tongue edges (scalloped tongue) (Figure 2). Biopsy of accessory salivary glands objectified noncaseating granulomas. Screening for systemic granulomatosis, connective tissue diseases, vasculitis, infections, and cancers was negative.

Free thyroxine was at $2 \mathrm{pmol} / \mathrm{l}$ and thyrotropin (TSH) at $120 \mu \mathrm{UI} /$ $\mathrm{ml}$. Anti-thyroperoxidase antibodies (anti-TPO) was strongly positive at $2180 \mathrm{UI} / \mathrm{ml}$ and anti-thyroglobulin antibodies at $328 \mathrm{UI} / \mathrm{ml}$ leading to the diagnosis of Hashimoto's thyroiditis associated to MRS.

Patient was treated with thyroxine in progressive doses normalizing $\mathrm{TSH}$, and systemic glucosteroids with a favorable outcome. No recurrence has been noted for five years now.

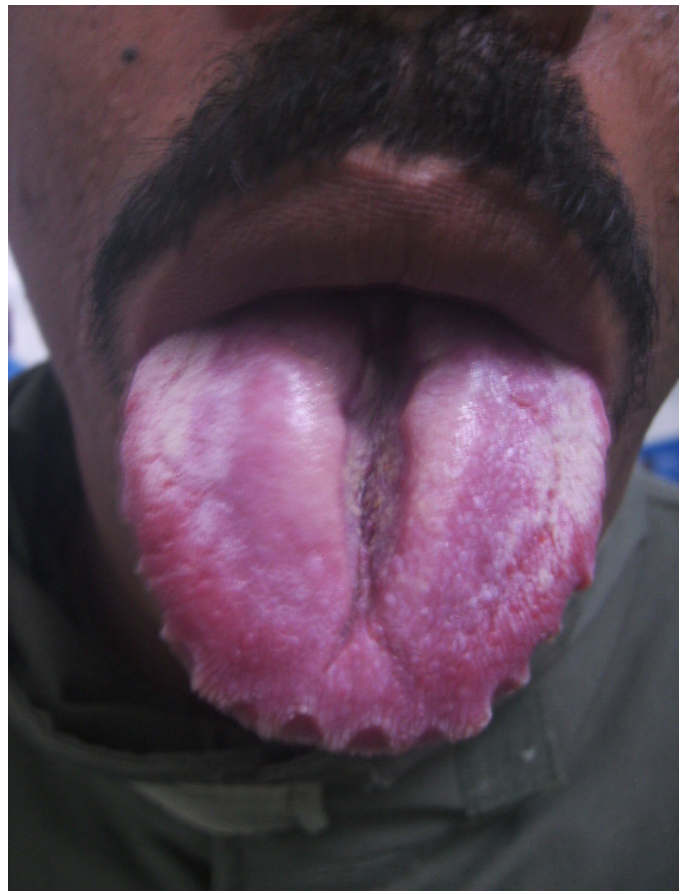

Figure 1. Macroglossia with fissured dorsal tongue (lingua plicata)

${ }^{\star}$ Correspondence to: Salem Bouomrani, Department of Internal medicine, Military Hospital of Gabes, Gabes 6000, Tunisia, E-mail: salembouomrani@ yahoo.fr

Key words: melkersson-rosenthal syndrome, autoimmune thyroiditis, hashimoto thyroiditis, lingua plicata

Received: December 05, 2019; Accepted: January 16, 2020; Published: January 20,2020 


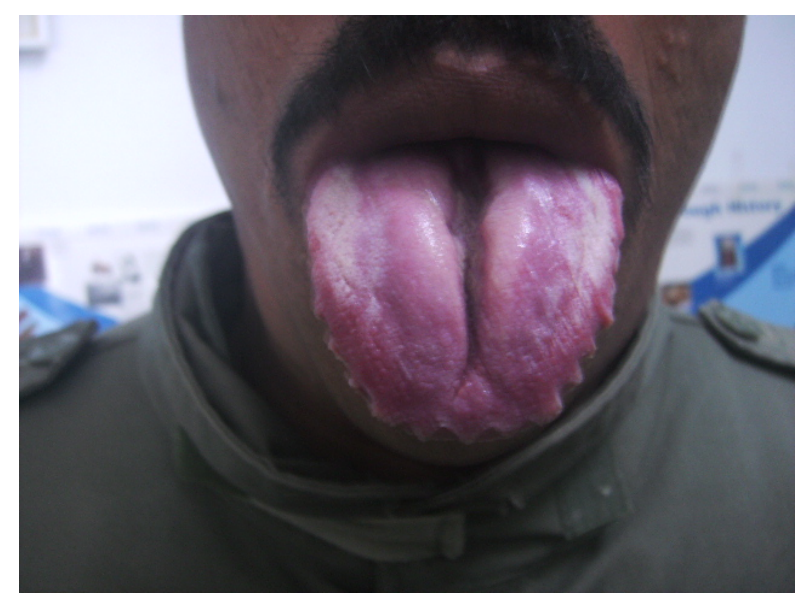

Figure 2. Teeth marks on tongue edges (scalloped tongue)

\section{Discussion}

The combination of MRS with autoimmune thyroiditis of Hashimoto remains exceptional and unusual; indeed, the review of the literature finds only two cases: Scagliusi P et al. [3], and Lee YJ et al. [4]. No case of this association was noted in the large series of Elias MK et al. [2] of the Mayo Clinic collecting 72 patients with MRS over a period of 40 years, among them 28 had comorbidities [2]. Our observation is to our knowledge the third reporting this association.
RMS may occur even in hypothyroid patients properly treated with clinical and biological euthyroidism. High levels of anti-thyroid antibodies, particularly anti-TPO, are associated with these MRS recurrences/relapses [4]. These findings reinforce the immunological hypothesis of MRS.

\section{Conclusion}

This association seems to be far from a mere coincidence. A common immunological hypothesis is evoked. Thus, a dosage of thyroid hormones and a screening for anti-thyroid antibodies would be useful in patients with an MRS.

\section{Conflicts of interest}

None.

\section{References}

1. Rivera-Serrano CM, Man LX, Klein S, Schaitkin BM (2014) Melkersson-Rosenthal syndrome: A facial nerve center perspective. J Plast Reconstr Aesthet Surg pii: S17486815(14)00176-4. [Crossref]

2. Elias MK, Mateen FJ, Weiler CR (2013) The Melkersson-Rosenthal syndrome: a retrospective study of biopsied cases. J Neurol 260: 138-143. [Crossref]

3. Scagliusi P, Sisto M, Lisi S, Lazzari A, D'Amore M (2008) Hashimoto's thyroiditi in Melkersson-Rosenthal syndrome patient: casual association or related diseases? Panminerva Med 50: 255-257. [Crossref]

4. Lee YJ, Cheon CK, Yeon GM, Kim YM, Nam SO (2014) Melkersson-Rosenthal syndrome with Hashimoto thyroiditis in a 9-year-old girl: an autoimmune disorder. Pediatr Neurol 50: 503-506. [Crossref]

Copyright: $@ 2020$ Bouomrani S. This is an open-access article distributed under the terms of the Creative Commons Attribution License, which permits unrestricted use, distribution, and reproduction in any medium, provided the original author and source are credited. 